\title{
Inappropriate prescribing: a systematic overview of published assessment tools
}

\author{
Carole P. Kaufmann • Regina Tremp • \\ Kurt E. Hersberger • Markus L. Lampert
}

Received: 10 May 2013 / Accepted: 7 August 2013/Published online: 10 September 2013

(C) Springer-Verlag Berlin Heidelberg 2013

\begin{abstract}
Background Criteria to assess the appropriateness of prescriptions might serve as a helpful guideline during professional training and in daily practice, with the aim to improve a patient's pharmacotherapy.

Objective To create a comprehensive and structured overview of existing tools to assess inappropriate prescribing.

Method Systematic literature search in Pubmed (1991-2013). The following properties of the tools were extracted and mapped in a structured way: approach (explicit, implicit), development method (consensus technique, expert panel, literature based), focused patient group, health care setting, and covered aspects of inappropriate prescribing.

Results The literature search resulted in 46 tools to assess inappropriate prescribing. Twenty-eight (61\%) of 46 tools were explicit, $8(17 \%)$ were implicit and $10(22 \%)$ used a mixed approach. Thirty-six (78\%) tools named older people as target patients and $10(22 \%)$ tools did not specify the target age group. Four (8.5\%) tools were designed to detect inappropriate prescribing in hospitalised patients, 9 (19.5\%) focused on patients in ambulatory care and $6(13 \%)$ were developed for use in long-term care. Twenty-seven (59\%) tools did not specify the health care setting. Consensus methods were applied in the development of 19 tools (41\%), the others were based on either simple expert panels $(13 ; 28 \%)$ or on a literature search $(11 ; 24 \%)$. For three tools $(7 \%)$ the development method was not described.

Conclusion This overview reveals the characteristics of 46 assessment tools and can serve as a summary to assist readers
\end{abstract}

C. P. Kaufmann $(\bowtie) \cdot$ R. Tremp $\cdot$ K. E. Hersberger $\cdot$ M. L. Lampert Pharmaceutical Care Research Group, University of Basel,

Klingelbergstrasse 50, 4056 Basel, Switzerland

e-mail: carole.kaufmann@unibas.ch

C. P. Kaufmann • M. L. Lampert

Clinical pharmacy, Kantonsspital Baselland,

Bruderholz, Switzerland in choosing a tool, either for research purposes or for daily practice use.

Keywords Drug-related problems · inappropriate prescribing $\cdot$ assessment tool $\cdot$ drug safety

\section{Introduction}

The appropriate prescription of medication should "maximise efficacy and safety, minimise cost, and respect patient's preferences" [1]. Choosing the most appropriate medication for each patient in order to achieve desired therapeutic outcomes is a challenge for healthcare professionals in their daily practice [2]. Criteria to assess the appropriateness of prescriptions and to improve a patient's pharmacotherapy might serve as a helpful guideline during professional training and on the job on a daily basis. In recent years, with inappropriate prescribing becoming an important public health concern, different tools to assess inappropriate prescribing have been developed and published. These tools show major differences in structure and content. They can be grouped roughly into implicit (judgement-based) and explicit (criterion-based) tools, and tools showing a combination of both approaches.

Explicit tools are usually developed from published reviews, expert opinions, and consensus techniques. These criterionbased tools are mostly drug-oriented and/or disease-oriented and can be applied with little or no clinical judgement [3]. Explicit criteria are generally used as rigid standards and neither address individual differences among patients, nor the complexity and appropriateness of entire medication regimens [2]. They need to be updated regularly to ensure their conclusiveness. Furthermore, each country has specific guidelines, standards and approved medications, which makes a countryspecific adaption of explicit criteria necessary. The advantages are the lower cost of application and a higher degree of fairness in ensuring a more equal care [4]. 
Implicit tools are judgement-based, patient-specific, and consider the patient's entire medication regimen [2]. Implicit criteria often depend on the user's knowledge, experience and attitude. They can also take into account patients' preferences. However, they may be time-consuming and can have low reliability [3].

The combination of both explicit and implicit criteria enables to link the advantages of each approach. Explicit guidelines serve as background to supply user's clinical judgement of patient's medication and implicit questions provide a patientspecific approach with mostly a small number of items.

Creating a valid tool for the assessment of the appropriateness of a medication requires adequate evidence. In areas of health care where higher levels of evidence (e.g. controlled trials) are missing, consensus techniques are useful methods to develop an evidence base. These group facilitation techniques were developed to explore the level of consensus among a group of experts, whereby consensus is reached by summarizing many opinions into a single, agreed-upon, refined opinion [5]. Combining expert opinions with evidence from the literature seems to be a good approach to create a valid, useful tool. Types of consensus techniques are the RAND appropriateness method, the Delphi technique and the nominal group technique (NGT). The RAND combines current scientific evidence with the opinion of elected experts. Panelists rate, meet for discussion and then re-rate issues of interest. The Delphi technique consists of multiple questionnaire rounds with feedback to the panelists between rounds and uses evidence-based literature as a basis but omits expert meetings. The NGT is widely used to generate and prioritize ideas but usually has no initial review of the current scientific literature [5].

Several publications summarize and compare selected existing tools to assess the appropriateness of prescribing [2, 6-11], but a comprehensive overview is still missing. The existing publications either focus on specific patient groups or only show just a small comparison of the most popular tools. Therefore, the objective of this study is to provide a systematic literature search to create a comprehensive and structured overview of all existing tools. A mapping will highlight their characteristics and will allow a comparison of the structure and the content of these tools.

\section{Methods}

Pubmed database search included the time period from January 1, 1991, to March 19, 2013. The search strategy contained the following terms and combinations: Inappropriate Prescribing [MESH] OR inappropriate prescribing [All Fields] OR inappropriate prescribing/classification [All Fields] OR inappropriate prescribing/economics [All Fields] OR inappropriate prescribing/ethics [All Fields] OR inappropriate prescribing/ history [All Fields] OR inappropriate prescribing/methods [All Fields] OR inappropriate prescribing/mortality [All Fields] OR inappropriate prescribing/nursing [All Fields] OR
Fig. 1 Flowchart of the literature search

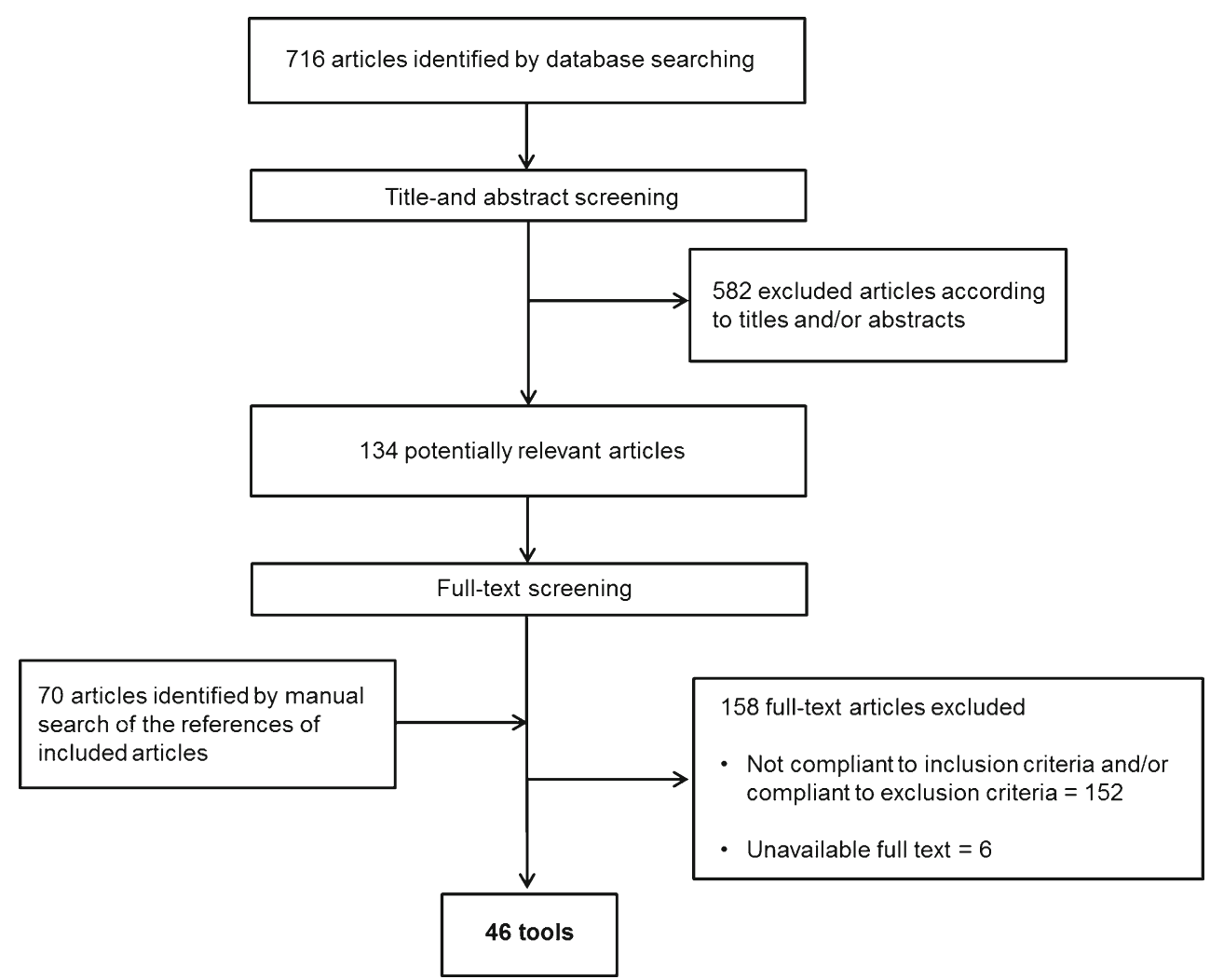


inappropriate prescribing/psychology [All Fields] OR inappropriate prescribing/trends [All Fields] OR inappropriate prescribing/utilization [All Fields] OR inappropriate prescribings [All Fields] OR inappropriate prescription [All Fields] OR inappropriate prescriptions [All Fields]. The MESH term "Inappropriate prescribing" was introduced only in 2011. Prior to this, "inappropriate prescribing" was included in the broadly defined MESH term "Drug therapy". We limited the search to studies in adults. Articles must have been published in English or German. The database search was completed with a manual search from the reference lists of included articles. The reviewer (RT) assessed publications for eligibility by title and abstract screening. Each article showing uncertainty regarding inclusion or exclusion criteria was discussed between three of the authors (RT, CK, ML).

Inclusion and exclusion criteria

We included articles describing tools or computerised decision support systems to assess inappropriate prescribing, updated versions of already published tools and adaptations of an already published tool if its further development was based on new expert consensus.

We defined the following exclusion criteria: Tools restricted to specific therapeutic classes (e.g., benzodiazepines, antibiotics, etc.), or specific diseases, tools targeted to children, adaption of already published tools to computerised decision support systems, medication review techniques which did not use a tool, educational interventions to improve prescribing practice, validation studies of previously published tools, and general guidelines or recommendations to assess inappropriate prescribing.

\section{Mapping of the tools}

We grouped the tools in three main domains (explicit, implicit and mixed tools). In every domain tools were ordered according the strength of evidence of their development method (consensus technique, expert panel, literature based). To highlight the characteristics of the tools we listed all properties in a structured way. We categorised inappropriate prescribing

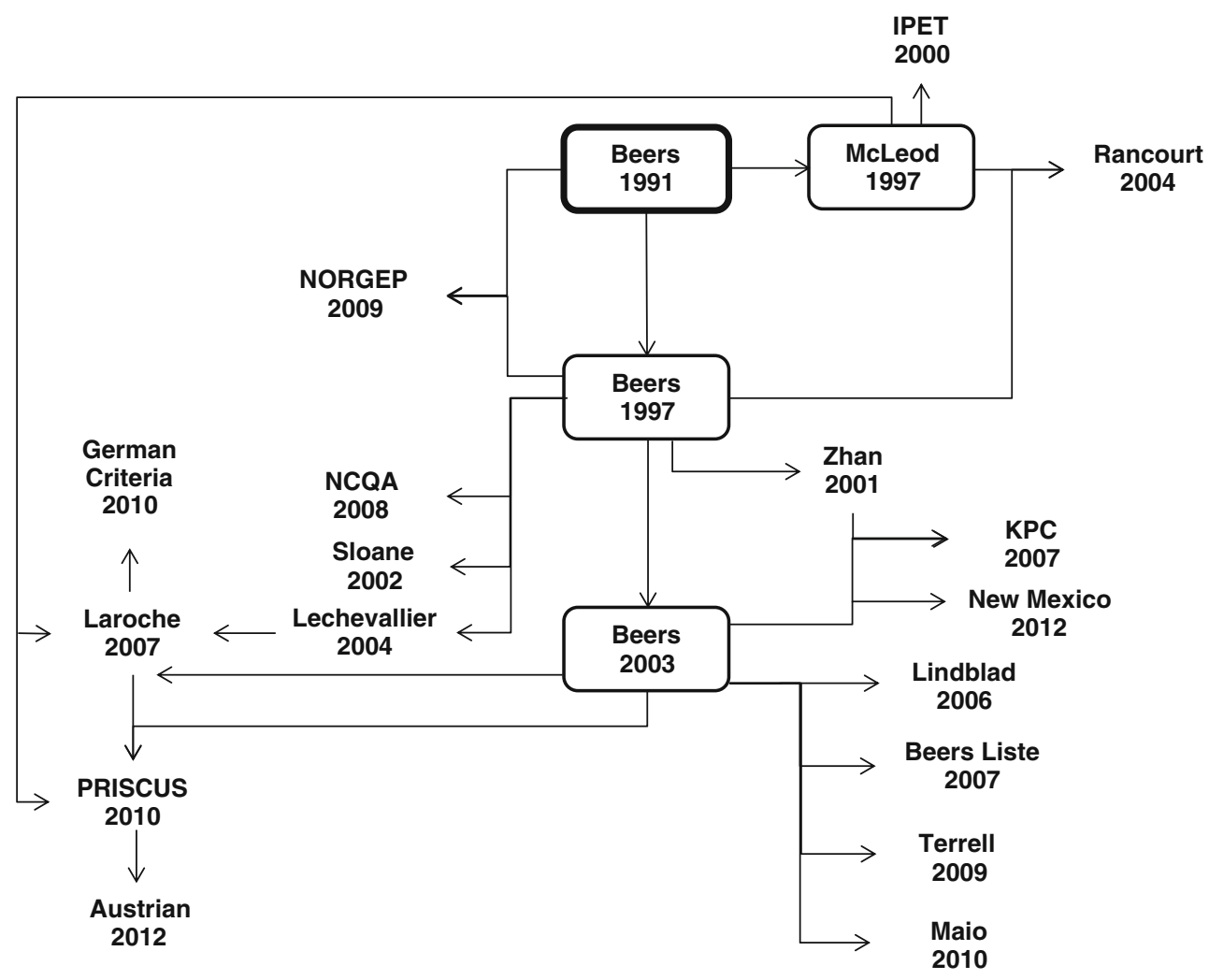

Fig. 2 Relation between different assessment tools. Tools in boxes represent criteria, most frequently used as basis for the development of other tools. (Austrian: Austrian Criteria [33]; Beers: Beers Criteria, different versions [19-21]; Beers Liste [34]; German Criteria: Unangemessene Arzneistoffe für geriatrische Patienten [55]; IPET: Improving Prescribing in the Elderly Tool [53]; KPC: Kaiser Permanente Colorado Criteria [49]; Laroche: Laroche Criteria [35]; Lechevallier : Lechevallier Criteria [50]; Lindblad : Lindblad's List of Clinically Important Drug-Disease Interactions [36];
Maio: Maio Criteria [47]; McLeod: McLeod Criteria [22]; NCQA: NCQA Criteria - High Risk Medications (DAE-A) and potentially harmful DrugDisease Interactions (DDE) in the Elderly [37]; New Mexico: New Mexico Criteria [51]; NORGEP: Norwegian General Practice Criteria [38]; PRISCUS: The PRISCUS List [43]; Rancourt: Rancourt Criteria [39]; Sloane: Sloane List of Inappropriate Prescribed Medicines [54]; Terrell: Terrell Computerized Decision Support System to reduce potentially inappropriate prescribing [26]; Zhan: Zhan Criteria [46]) 
Table 1 Explicit tools to assess inappropriate prescribing

\begin{tabular}{|c|c|c|c|c|c|c|c|c|c|c|c|c|c|c|c|}
\hline \multirow[b]{3}{*}{ 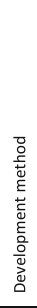 } & \multirow{4}{*}{$\begin{array}{l}\text { ACOVE QIs - Assessing Care of Vulnerable Elders Quality Indicators [30,31] (USA, 1999) } \\
\text { A set of QIs to measure the medical care provided to vulnerable, older persons, created in 1999 and twice updated in 2001 (ACOVE-2, } \\
\text { http://www.rand.org/content/dam/rand/www/external/health/projects/acove/docs/acove_qi.pdf) and } 2006 \text { (ACOVE-3) [32]. All ACOVE Qls } \\
\text { are presented in the following format: IF-THEN-(BECAUSE). Not all Qls measure aspects of inappropriate prescribing but some consider } \\
\text { inappropriate prescribing. } \\
\text { ACOVE-1 (1999) covers } 22 \text { clinical conditions and } 236 \text { quality indicators. } \\
\text { ACOVE-3 (2006) covers } 26 \text { clinical conditions and includes } 392 \text { quality indicators. }\end{array}$} & \multirow[b]{3}{*}{ 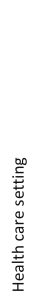 } & \multirow[b]{3}{*}{ 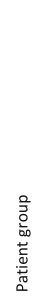 } & \multicolumn{12}{|c|}{ Aspects of inappropriateness } \\
\hline & & & & \multicolumn{7}{|c|}{ Misprescribing } & & & \multirow[b]{2}{*}{ 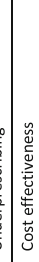 } & \multirow[b]{2}{*}{ 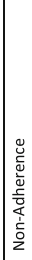 } & \multirow[b]{2}{*}{ 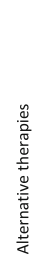 } \\
\hline & & & & & 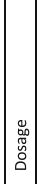 & & 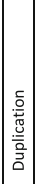 & 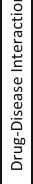 & 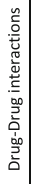 & 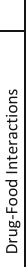 & & & & & \\
\hline RD & & ns & $E I$ & $\bullet$ & & & & $\circ$ & & & & $\circ$ & & & $\circ$ \\
\hline$D p$ & $\begin{array}{l}\text { Austrian Criteria [33] (Austria, 2012) } \\
\text { A list of } 73 \text { drugs to avoid in older patients because of an unfavourable benefit/risk profile and/or unproven effectiveness. A justification for } \\
\text { the inappropriateness of a specific drug or drug class is given and for some of the drugs safer alternatives are proposed. }\end{array}$ & ns & $E I$ & $\bullet$ & & & & & & & & & & & $\circ$ \\
\hline $\mathrm{Dp}$ & $\begin{array}{l}\text { Beers Criteria [19] (USA, 1991) } \\
\text { The Beers Criteria, originally developed for nursing home residents, consists of } 19 \text { medications or medications classes to avoid generally in } \\
\text { the elderly and } 11 \text { criteria describing doses, frequencies, or durations that should not be exceeded. } \\
\text { Update 1997[20]: } 28 \text { medications or medication classes to avoid generally in the elderly and } 15 \text { diseases and conditions and medications to } \\
\text { be avoided in these conditions } \\
\text { Update } 2003[21]: 48 \text { medications or medication classes to avoid generally in the elderly and } 20 \text { diseases and conditions and medications to } \\
\text { be avoided in these conditions } \\
\text { Update 2012[29]: } 34 \text { medications or medication classes to avoid in the elderly and } 14 \text { diseases and conditions and medications to be } \\
\text { avoided in these conditions, and } 5 \text { medications to be used with caution in older adults. }\end{array}$ & $n s$ & $E l$ & $\bullet$ & 0 & $\circ$ & & $\circ$ & & & & & & & $\circ$ \\
\hline $\mathrm{Dp}$ & $\begin{array}{l}\text { Beers-Liste [34] (Germany, 2007) } \\
\text { German adaption of Beers Criteria 2003. Structure and content are similar to the original Beers Criteria, but have been adapted for the } \\
\text { German Market. }\end{array}$ & ns & $E I$ & $\bullet$ & 0 & $\circ$ & & $\bullet$ & & & & & & & $\circ$ \\
\hline $\mathrm{Dp}$ & $\begin{array}{l}\text { Laroche Criteria [35] (France, 2007) } \\
\text { Designed for use in the French health care system, including } 34 \text { medications to be avoided in elderly. Each drug has a declaration for its } \\
\text { inappropriateness and safer therapeutic alternatives were recommended for most of the criteria. }\end{array}$ & ns & $E I$ & $\bullet$ & 0 & & 0 & $\circ$ & $\circ$ & & & & & & $\circ$ \\
\hline $\mathrm{Dp}$ & $\begin{array}{l}\text { Lindblad's List of Clinically Important Drug-Disease Interactions [36] (USA, 2006) } \\
\text { A consensus list of } 28 \text { clinically important drug-disease interactions ordered by disease. }\end{array}$ & $A$ & $E I$ & $\bullet$ & & & & $\bullet$ & & & & & & & \\
\hline$D p$ & $\begin{array}{l}\text { Malones List of Drug-Drug Interactions [24] (USA, 2004) } \\
\text { A list of } 25 \text { potential harmful drug-drug interactions with clinical importance, designed for use in community pharmacies, implemented in a } \\
\text { computerized alert system. }\end{array}$ & $A$ & ns & $\bullet$ & & & & & $\bullet$ & & & & & & \\
\hline $\mathrm{Dp}$ & $\begin{array}{l}\text { McLeod Criteria [22] (Canada, 1997) } \\
\text { Includes } 38 \text { inappropriate prescribing practices to avoid in elderly, focused on four main topics: 1) drugs to treat cardiovascular diseases, 2) } \\
\text { non-steroidal anti-inflammatory drugs and other analgesics, 3) psychotropic drugs, and 4) miscellaneous drugs. For each practice, the risk to } \\
\text { the patient is specified and an alternative therapy is suggested. }\end{array}$ & ns & $E l$ & $\bullet$ & & $\circ$ & & $\circ$ & $\circ$ & & & & & & $\bullet$ \\
\hline $\mathrm{Dp}$ & $\begin{array}{l}\text { NCQA Criteria - High Risk Medications (DAE-A) and potentially harmful Drug-Disease Interactions (DDE) in the } \\
\text { Elderly [37] (USA,2008) } \\
\text { The DAE-A and the DDE lists are part of the Health Care Effectiveness Data Information Set (HEDIS), a tool to measure performance on } \\
\text { important dimensions of care and a service developed by the National Committee for Quality Assurance (NCQA). The DAE-A list includes } 17 \\
\text { medication classes which should be avoided in the elderly, the DDE list shows medication categories affecting the condition of the elderly in } \\
\text { a negative way. As a part of HEDIS, the DAE-A and DDE lists are available as interactive, web-based reporting software and receive regular } \\
\text { updates. }\end{array}$ & ns & $E I$ & $\bullet$ & & & & $\circ$ & & & & & & & \\
\hline $\mathrm{Dp}$ & $\begin{array}{l}\text { NORGEP - Norwegian General Practice Criteria [38] (Norway, 2009) } \\
\text { A list of } 21 \text { drugs and drug dosages, as well as } 15 \text { drug combinations to be avoided in the elderly in general practice. Each criterion is } \\
\text { specified by a comment. }\end{array}$ & $A$ & $E l$ & $\bullet$ & $\circ$ & & & & $\bullet$ & & & & & & \\
\hline$D p$ & $\begin{array}{l}\text { Rancourt Criteria [39] (Canada, 2004) } \\
\text { Consists of a list of } 111 \text { potentially inappropriate prescriptions categorized as 1) Potentially inappropriate medication, 2) Potentially } \\
\text { inappropriate dosage 3) Potentially inappropriate duration and 4) Potentially inappropriate drug-drug interaction. }\end{array}$ & $L$ & $E I$ & $\bullet$ & 0 & $\circ$ & & & $\bullet$ & & & & & & \\
\hline $\mathrm{Dp}$ & $\begin{array}{l}\text { START - Screening Tool to Alert doctors to the Right Treatment [40] (Ireland, 2007) } \\
\text { A list of } 22 \text { prescribing indicators to identify prescribing omissions in older adults. The prescribing indicators are arranged according to the } \\
\text { physiological system and present information about disease status for which a drug should be prescribed. Combining this tool with STOPP } \\
\text { (see directly below) is possible. }\end{array}$ & ns & $E I$ & $\bullet$ & & $\circ$ & & & & & & & & & \\
\hline $\mathrm{Dp}$ & $\begin{array}{l}\text { STOPP - Screening Tool of Older Person's Prescriptions [41,42] (Ireland, 2008) } \\
65 \text { criteria focusing on prevalent problems associated with commonly prescribed medication, arranged according to physiological systems. } \\
\text { Each criterion is accompanied by a short explanation concerning the inappropriateness of its use. }\end{array}$ & $n s$ & $E I$ & $\bullet$ & 0 & $\circ$ & $\bullet$ & 0 & $\circ$ & & & & & & \\
\hline $\mathrm{Dp}$ & $\begin{array}{l}\text { The PRISCUS List [43] (Germany, 2010) } \\
\text { Consists of } 83 \text { potentially inappropriate medications in a total of } 18 \text { medication classes and is designed for use in the German health care } \\
\text { system. For each inappropriate medication, the criteria include main concerns, possible therapeutic alternatives and precautions to be } \\
\text { taken when these medications are used. The freely available online version[44] additionally focuses on drug-disease interactions. }\end{array}$ & ns & $E I$ & $\bullet$ & 0 & & & • & & & & & & & \\
\hline $\mathrm{Dp}$ & $\begin{array}{l}\text { Winit-Watjana Criteria [45] (Thailand, 2008) } \\
\text { The list consists of } 77 \text { high-risk drugs divided into drugs to be avoided; drugs rarely appropriate; and drugs with some indications for older } \\
\text { patients. A practice statement for each drug gives additional information about the inappropriateness. }\end{array}$ & $n s$ & $E l$ & $\bullet$ & & & & 0 & $\circ$ & & & & & & \\
\hline $\mathrm{Dp}$ & $\begin{array}{l}\text { Zhan Criteria [46] (USA, 2001) } \\
\text { Includes } 33 \text { potentially inappropriate medications divided into the categories: 1) drugs to avoid 2) drugs, appropriate in rare circumstances } \\
\text { and 3) drugs with some indications but often misused. }\end{array}$ & $A$ & $E I$ & $\bullet$ & & & & & & & & & & & \\
\hline $\begin{array}{l}\text { NG } \\
T\end{array}$ & $\begin{array}{l}\text { Maio Criteria [47] (Italy, 2010) } \\
\text { The Italian adaption of Beers Criteria 2003. The criteria contain } 23 \text { potentially inappropriate drugs and divide them into three categories: 1) } \\
\text { Drugs to always be avoided, 2) Drugs rarely appropriate, and 3) Drugs with some indications but often misused. }\end{array}$ & $A$ & $E I$ & $\bullet$ & 0 & $\circ$ & & & & & & & & & \\
\hline
\end{tabular}


Table 1 (continued)

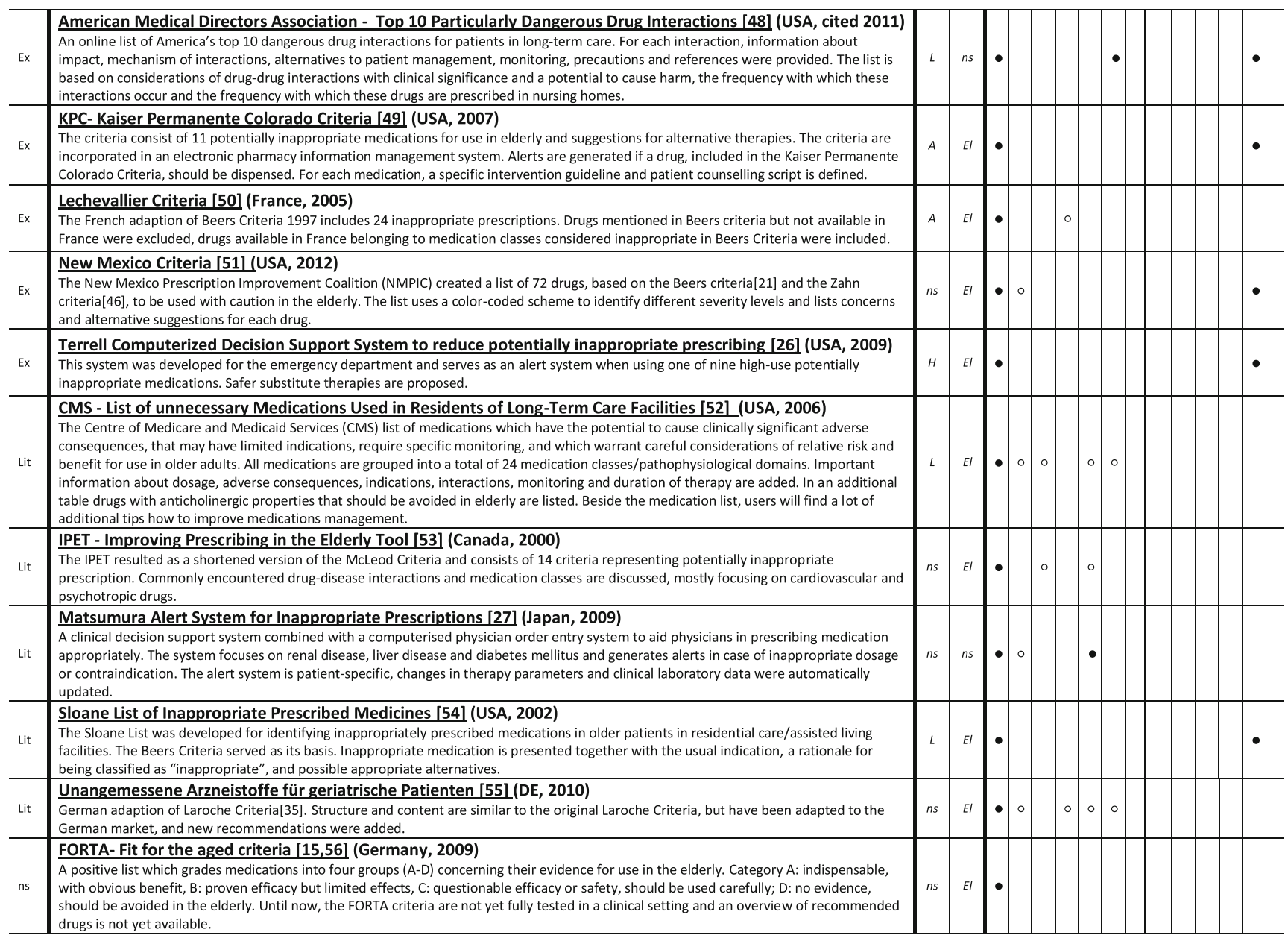

$\bullet=$ Aspect totally covered by the criteria. $\bigcirc=$ Aspect partially covered by the criteria

Abbreviations:

RD RAND method; Dp Delphi method; NGT Nominal group technique; Ex Expert panel; Lit based on literature research; El Elderly; L Patients in long-term care; H Hospitalized patients; A Ambulatory patients; ns not specified

according to Spinewine [3] into underprescribing, overprescribing and misprescribing and defined these terms as follows $[12,13]$ :

Underprescribing: The omission of a medication that is needed (no therapy for a given indication)

Overprescribing: The prescription of a medication that is clinically not indicated (unnecessary therapy)

Misprescribing: The incorrect prescription of an indicated medication.

We further divided misprescribing in:

- Drug choice: Better alternatives are available (better riskbenefit ratio or better cost-effectiveness)

- Dosage: Prescribed dose too low or too high or not correctly adapted to patient characteristics (e.g. renal function, body weight.)
- Duration of therapy: Duration of therapy too long or too short

- Duplication: Inappropriate prescription of drugs of the same pharmacological class

- Drug-Disease, Drug-Drug, Drug-Food Interactions: Combination of a drug with another drug, with food or with a medical condition with a potential or manifest negative impact on the therapeutic outcome

We listed the focused patient group (elderly, all age), and health care setting (hospital care, ambulatory care, long-term care). In addition, we added adherence, cost-effectiveness and whether the tool suggested alternative therapies to the inappropriate ones. The aspect of adherence represents, to a certain extent, the patients' preferences. Intentional non-adherence reflects patients' unwillingness to take their medication, mostly 
Table 2 Implicit tools to assess inappropriate prescribing

\begin{tabular}{|c|c|c|c|c|c|c|c|c|c|c|c|c|c|c|c|}
\hline \multirow[b]{3}{*}{ 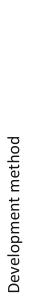 } & & \multirow[b]{3}{*}{ 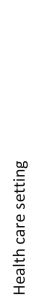 } & \multirow[b]{3}{*}{ 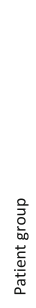 } & \multicolumn{12}{|c|}{ Aspects of inappropriateness } \\
\hline & & & & \multicolumn{7}{|c|}{ Misprescribing } & \multirow[b]{2}{*}{ סू. } & \multirow[b]{2}{*}{ 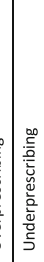 } & & & \multirow[b]{2}{*}{ 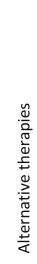 } \\
\hline & & & & 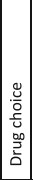 & 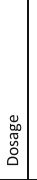 & 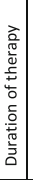 & 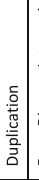 & 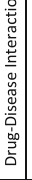 & 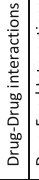 & 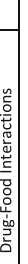 & & & & 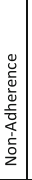 & \\
\hline $\mathrm{Dp}$ & $\begin{array}{l}\text { Cantrill Indicators of Appropriateness of long term prescribing [57] (UK, 1998) } \\
\text { Nine indicators of prescribing appropriateness for assessing the entire drug regimen of patients on long term medication in general practice. }\end{array}$ & L & ns & $\bullet$ & $\bullet$ & $\bullet$ & & & $\bullet$ & & $\bullet$ & & $\bullet$ & & \\
\hline Ex & $\begin{array}{l}\text { Lipton's Tool to assess the Appropriateness of Physicians' Geriatric Drug Prescribing [58] (USA, 1992) } \\
\text { Evaluation of each drug in the patient's regimen in seven categories of potential drug-therapy problems: 1) Drug allergy, 2) Drug dosage, 3) } \\
\text { Drug schedule, 4) Appropriateness of drug therapy, 5) Drug-drug interactions, 6) Therapeutic duplication and 7) Prescribing omission. For all } \\
\text { categories, a score is given: } 0=\text { no problem, } 1=c \text { clinically significant but not life-threatening, } 2=\text { potentially life threatening or potentially } \\
\text { leading to serious injury or hospitalisation; } 9=\text { not enough clinical information to make an assessment. }\end{array}$ & $n s$ & El & $\bullet$ & $\bullet$ & & $\bullet$ & & $\bullet$ & & $\bullet$ & $\bullet$ & & & \\
\hline Ex & $\begin{array}{l}\text { MAl - Medication Appropriateness Index [23] (USA, 1992) } \\
\text { Ten questions used to assess medication appropriateness, which are answered using a three-point Likert scale. For each criterion, a rating of } \\
1 \text { represents appropriate medication use; a rating of } 2 \text { represents marginally appropriate medication use; and a rating of } 3 \text { represents } \\
\text { inappropriate use. }\end{array}$ & $n s$ & ns & - & $\bullet$ & $\bullet$ & $\bullet$ & $\bullet$ & $\bullet$ & & $\bullet$ & & $\bullet$ & & \\
\hline Ex & $\begin{array}{l}\text { PMDRP - Pharmacist's Management of Drug-Related Problems [59] (Canada, 1997) } \\
\text { Developed by pharmacists to facilitate learning and the better provision of pharmaceutical care. It requires the pharmacists to collect } \\
\text { patients' clinical and medical data and serves as a comprehensive documentation system guiding the pharmacists through the whole } \\
\text { pharmaceutical care process. }\end{array}$ & $n s$ & ns & $\bullet$ & $\bullet$ & & & $\bullet$ & $\bullet$ & & $\bullet$ & $\bullet$ & & $\bullet$ & \\
\hline Lit & $\begin{array}{l}\text { Barenholtz Levy self-administered Medication-Risk Questionnaire [28] (USA, 2003) } \\
\text { Ten-item, self-administered questionnaire for use by elderly patients to identify who is at increased risk of potentially experiencing a } \\
\text { medication-related problem. }\end{array}$ & $n s$ & El & $\bullet$ & & & & & & & $\bullet$ & & & $\bullet$ & \\
\hline Lit & $\begin{array}{l}\text { Hamdy Criteria for Medication Profile Review in Extended Care [60] (USA, 1995) } \\
\text { The criteria were developed with the aim of reducing polypharmacy in patients in long-term care. Five open questions assess the } \\
\text { appropriateness of patients' medication focusing on patients taking } 10 \text { or more medications. }\end{array}$ & $L$ & ns & - & $\bullet$ & $\bullet$ & $\bullet$ & $\bullet$ & $\bullet$ & & $\bullet$ & & & & \\
\hline Lit & $\begin{array}{l}\text { Owens Steps to achieve optimal Pharmacotherapy [61] (USA, 1994) } \\
\text { Consists of five questions: 1) Diagnosis: Is pharmacological intervention necessary? 2) Drug appropriateness? 3) Dose appropriateness? } \\
\text { Pharmacokinetic and pharmacodynamic parameters; 4) Reassess: Is medication still needed? 5) Drug-induced disease. }\end{array}$ & ns & $E I$ & $\bullet$ & $\bullet$ & $\bullet$ & & $\bullet$ & & & $\bullet$ & & & & \\
\hline ns & $\begin{array}{l}\text { Robertson's Flow Charts to prevent, identify and resolve Drug Therapy Problems [14] (USA, 1996) } \\
\text { Robertson's Flow Charts were developed to help pharmacy students to focus on drug therapy issues during clinical clerkship rotations. Ten } \\
\text { flow charts encourage a uniform approach to preventing, identifying, and correcting drug therapy problems. }\end{array}$ & $H$ & ns & $\bullet$ & $\bullet$ & & & $\circ$ & $\bullet$ & & $\bullet$ & & $\circ$ & $\bullet$ & \\
\hline
\end{tabular}

- = Aspect totally covered by the criteria. $\bigcirc=$ Aspect partially covered by the criteria

Abbreviations:

RD RAND method; Dp Delphi method; NGT Nominal group technique; Ex Expert panel; Lit based on literature research; El Elderly; L Patients in longterm care; H Hospitalized patients; A Ambulatory patients; ns not specified

caused by a therapy regimen which does not respect their preferences and, according to Barber's definition [1], is therefore inappropriate.

\section{Results}

A total of 716 articles was identified through database search. The numbers of included and excluded articles at each stage are displayed in a flowchart (see Fig. 1). In the end, 46 publications met the inclusion criteria and described 46 different tools. Twenty (43\%) of the 46 tools were related to previously published tools (see Fig. 2).

\section{Characteristics (see Table 1, 2 and 3)}

Twenty-eight (61\%) of 46 tools were explicit, 8 (17\%) were implicit and 10 (22\%) used a mixed approach. Looking at the patient groups the tools focused on, thirty-six (78\%) tools named older people as target patients and $10(22 \%)$ tools did not specify the target age group. Four $(8.5 \%)$ tools were designed to detect inappropriate prescribing in hospitalised patients, $9(19.5 \%)$ focused on patients in ambulatory care and $6(13 \%)$ were developed for use in long-term care. Twentyseven $(59 \%)$ tools did not specify the health care setting. Consensus methods were applied in the development of 19 tools (41\%; RAND 2, Delphi technique 16, Nominal group technique $1)$, the others were based on either simple expert panels (13, $28 \%$ ) or on a literature search $(11,24 \%)$. For three tools $(7 \%)$ the development method was not described [14-16].

\section{Aspects of inappropriate prescribing}

The aspect of misprescribing was covered to a different extent by each tool. Fourteen (30\%) tools focused on overprescribing, $6(13 \%)$ on underprescribing, 8 (17\%) mentioned nonadherence and $5(11 \%)$ the cost-effectiveness. Fourteen $(30 \%)$ tools offered alternative therapies.

\section{Discussion}

The rapidly growing number of publications about inappropriate prescribing demonstrates the increased interest in this topic over 
Table 3 Tools with a mixed approach (explicit/implicit) to assess inappropriate prescribing

\begin{tabular}{|c|c|c|c|c|c|c|c|c|c|c|c|c|c|c|c|}
\hline \multirow[b]{3}{*}{ 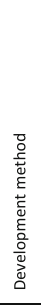 } & & \multirow[b]{3}{*}{ 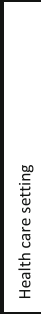 } & \multirow[b]{3}{*}{ 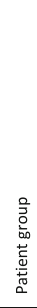 } & \multicolumn{12}{|c|}{ Aspects of inappropriateness } \\
\hline & & & & \multicolumn{7}{|c|}{ Misprescribing } & \multirow[b]{2}{*}{ 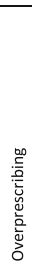 } & \multirow[b]{2}{*}{ 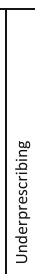 } & & \multirow[b]{2}{*}{ 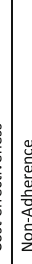 } & \multirow[b]{2}{*}{ 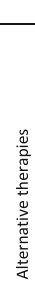 } \\
\hline & & & & 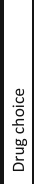 & 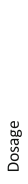 & 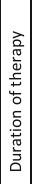 & 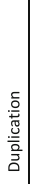 & 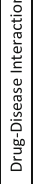 & 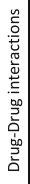 & 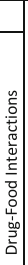 & & & & & \\
\hline$R D$ & $\begin{array}{l}\text { Australian Prescribing Indicators [62,63] (Australia, 2008) } \\
\text { A list of } 41 \text { indicators is presented based on the medications most frequently prescribed to Australians and the most frequent medical } \\
\text { conditions in the elderly. An additional list provides criteria usage information containing necessary medical information for each criterion. }\end{array}$ & ns & $E I$ & $\bullet$ & $\circ$ & 0 & & $\circ$ & $\bullet$ & & $\circ$ & $\circ$ & & & \\
\hline$E x$ & $\begin{array}{l}\text { Brown Model for Improving Medication Use in Home Health Care Patients [64] (USA, 1998) } \\
\text { A list of } 15 \text { potential medication problems occurring in patients receiving home health care. A structured procedure is described, where } \\
\text { home health nurses, in consultation with a drug utilisation review coordinator (e.g. clinical pharmacist), present problems and potential } \\
\text { solutions to the patient's physician. }\end{array}$ & $A$ & El & $\bullet$ & $\bullet$ & & $\bullet$ & 0 & & & & & & & $\circ$ \\
\hline$E x$ & $\begin{array}{l}\text { Indicators for Quality Use of Medicines [65] (Australia, 2007) } \\
\text { The New South Wales Advisory Group Quality Indicators were developed for the monitoring of aspects of care in Australian hospitals. Not all } \\
\text { of the } 30 \text { mentioned indicators consider aspects of prescribing. Each indicator is clearly described and usage information is provided. }\end{array}$ & $H$ & ns & 0 & $\circ$ & & & & & & & & & & \\
\hline$E x$ & $\begin{array}{l}\text { Oborne's Prescribing Indicators [66] (UK, 1997) } \\
\text { A list of } 14 \text { prescribing indicators based on the drug charts of } 1686 \text { patients. The indicators were presented in the form of algorithms guiding } \\
\text { the user through the process of detecting inappropriate prescribing. A version of Prescribing Indicators thought for use in nursing homes is } \\
\text { available[67] }\end{array}$ & $H$ & $E I$ & $\bullet$ & $\circ$ & & $\circ$ & $\circ$ & & & $\circ$ & $\circ$ & & & \\
\hline$E x$ & $\begin{array}{l}\text { TIMER - Tool to Improve Medications in the Elderly via Review [68] (USA, 2009) } \\
\text { Developed to help pharmacists and pharmacy students identify drug-related problems during patient medication reviews. TIMER addresses } \\
\text { four main categories: 1) Cost-effectiveness, 2) Adherence, 3) Medication safety, with methods to assess ADEs and drug-drug interactions 4) } \\
\text { Attaining therapeutic goals }\end{array}$ & ns & $E I$ & $\bullet$ & & & $\bullet$ & $\circ$ & $\bullet$ & & & & $\bullet$ & $\bullet$ & \\
\hline$E x$ & $\begin{array}{l}\text { The Geriatric Medication Algorithm [69] (USA, 1994) } \\
\text { Designed to educate physicians in reducing inappropriate prescribing, divided into four steps: 1) Obtaining a complete medication list from } \\
\text { patient and orthostatic blood pressure; 2) Evaluating each drug regarding indication, high risk medications and dosage; 3) Evaluating the } \\
\text { entire drug regimen regarding drug-drug interactions and simplification of drug regimen; 4) Evaluating adherence. Some explicit lists of high } \\
\text { risk drugs and drugs requiring dosage reduction in the elderly are also provided. }\end{array}$ & ns & $E I$ & $\bullet$ & • & & & $\bullet$ & $\bullet$ & & $\bullet$ & & & $\bullet$ & \\
\hline Lit & $\begin{array}{l}\text { Kaiser Permanente Model [70] (USA, 1995) } \\
\text { Consists of a pathway for determining high risk patients, then guides the pharmacist with a list through Rx-validation and dispensing, and } \\
\text { offers drug grids in order to improve appropriate interventions. }\end{array}$ & $A$ & ns & $\bullet$ & $\bullet$ & & $\bullet$ & $\bullet$ & $\bullet$ & & & & & $\bullet$ & \\
\hline Lit & $\begin{array}{l}\text { Medication Management Outcomes Monitor[71] (USA, 2006) } \\
\text { The criteria focus on reducing inappropriate prescribing (including medication from Beers Criteria 1991), decreasing polypharmacy, avoiding } \\
\text { adverse events and maintaining the functional status of older adults. Those four major outcomes serve as an outline and are divided into } \\
\text { several specific subgroups, each containing bibliographical references or guidelines on how to assess or intervene. These guidelines are to } \\
\text { be used by registered nurses, nurse practitioners, and pharmacists. }\end{array}$ & ns & $E l$ & $\bullet$ & $\bullet$ & & $\bullet$ & & & & $\bullet$ & & $\bullet$ & $\bullet$ & \\
\hline Lit & $\begin{array}{l}\text { POM - Prescribing Optimisation Method for Improving Prescribing in Elderly Patients [72] (Netherlands, 2009) } \\
\text { POM assists physicians to optimise polypharmacy prescribing in the elderly population. This method is based on six open questions, } \\
\text { whereby each question in presented with an overview of the most frequent and clinically relevant problems, together with explicit } \\
\text { suggestions to improve prescribing. }\end{array}$ & $n s$ & $E I$ & $\bullet$ & - & & & $\bullet$ & $\bullet$ & & $\bullet$ & • & & $\bullet$ & $\circ$ \\
\hline ns & $\begin{array}{l}\text { ARMOR-A Tool to Evaluate Polypharmacy in Elderly Persons [16] (USA, 2009) } \\
\text { ARMOR is a stepwise approach for the assessment of a geriatric patient who is: (1) receiving nine or more medications; (2) seen for initial } \\
\text { assessment; (3) seen for falls and/or changes in behaviour; and/or (4) admitted for rehabilitation. The tool consists of five steps: Assess } \\
\text { (medication), Review (e.g. interactions), Minimise (nonessential drugs), Optimise (e.g. Duplication, Dose adjustment) and Reassess (e.g. } \\
\text { blood pressure). }\end{array}$ & ns & $E I$ & $\bullet$ & - & & $\bullet$ & $\bullet$ & $\bullet$ & & $\bullet$ & & & & \\
\hline
\end{tabular}

$\bullet=$ Aspect totally covered by the criteria. $\circ=$ Aspect partially covered by the criteria

Abbreviations:

RD RAND method; Dp Delphi method; NGT Nominal Group Technique; Ex Expert panel; Lit based on literature research; El Elderly; L Patients in long-term care; H Hospitalized patients; A Ambulatory patients; ns not specified

the last decade. Many attempts have been made to improve drug prescribing. Tools to achieve this aim are numerous, as we show in this overview, each with a different structure and degree of comprehensiveness and complexity. Many of them might serve as a useful aid to improve prescribing, but each tool has its limitations, strengths and weaknesses. In general, an ideal tool to assess the appropriateness of drug prescriptions should:

- cover all aspects of appropriateness (efficacy, safety, costeffectiveness and patients' preferences)

- be developed using evidence-based methods

- show significant correlation between the degree of inappropriateness and clinical outcomes
- be applicable not only in research conditions but also in daily health care practice

None of the tools we describe in this systematic overview covers all aspects of inappropriate prescribing. In particular, underprescribing is only mentioned in 6 tools, although underprescribing represents an important aspect of inappropriate prescribing and is prevalent particularly in the elderly [17]. Many tools strongly emphasize the choice of a drug which leads to a better compliance with treatment guidelines. But respecting all relevant treatment guidelines without individualisation is in the best case rational prescribing but not necessarily appropriate prescribing [18]. Individualisation is therefore a prerequisite for 
appropriate prescribing and, thus, the drug-patient interaction is implicitly included in any aspect of appropriate prescribing.

The development methods of the tools we mapped varied a lot and ranged from those which included no information about any aspects of development, to those which used an intensive literature search combined with multiple consensus techniques.

The results obtained from the use of any of the tools represent process measures. Improving the patient's prescription according to such a tool does not necessarily improve outcomes (e.g. mortality, morbidity, adverse drug events, quality of life, etc.). Correlations between process measures and clinical outcomes should be demonstrated in welldesigned clinical trials. For the majority (39/46) of the tools we could not find such clinical validation in the literature.

In a systematic review, Spinewine et al. [3] analysed the correlation between the use of inappropriate medications according to the Beers Criteria [19-21], the McLeod's Criteria [22], and the Medication Appropriateness Index [23] and patient outcomes: Many studies examined the Beers Criteria and showed a significant correlation of potentially inappropriate medication (PIM) and negative clinical outcomes (e.g., mortality, adverse drug reactions, hospital admission). Additional studies not included in Spinewine's review showed evidence that minimizing inappropriate prescriptions may reduce negative patient outcomes (see Table 4).

Assessment tools are not intended as a substitute for the prescriber's careful clinical decision-making, even if they have been perfectly validated. Instead, when implemented in daily practice, they alert health care professionals to the likelihood of inappropriate prescribing [9]. Such implementation, however, requires that tools should not only be well designed and comprehensive, but also still practical in daily use. Integration of assessment tools in electronic decision support systems could be a promising approach [24-27]. One tool, the BarenholtzLevy Medication Risk Questionnaire [28] is designed for selfassessment by the patient which represents a very different strategy.

A short description of each tool including the number of items, where assessable (cf. Table 1, 2 and 3), provides some information about the construction and complexity. The number of items per tool varies a lot and ranges from less than ten to more than a hundred items. However a direct relation between the number of items and the complexity of a tool is not clearly given. As an example: the implicit Medication Appropriateness Index (MAI) [23] consists of only 10 questions to patient's medication. But the application of the MAI requires clinical knowledge and is time intensive. On the other hand the explicit Beers Criteria [29], with a high number of items, but arranged in a comprehensive way is easy to handle for a person who is used to it.

\section{Limitations}

The literature search was restricted to articles published in English and German; criteria published in other languages were reasonably not included because analysing and mapping the tools required a complete understanding of the text. Literature search, abstract and full text screening were done by only one of the authors (RT). Uncertainties were discussed by all authors. The mapping was developed by one author (RT) and reviewed by a second (CK). Uncertainties about eligibility
Table 4 Correlation of inappropriate prescribing with adverse patient outcomes

\begin{tabular}{|c|c|c|}
\hline Tool & Outcomes & References \\
\hline Beers Criteria & $\begin{array}{l}\text { - higher probability of hospitalization with } 2 \\
\text { or more potentially inappropriate } \\
\text { medications (PIM) } \\
\text { - significantly increased risk for ADRs in } \\
\text { elderly with at least one PIM } \\
\text { - increased risk of hospitalisation and } \\
\text { death with PIM } \\
\text { - increased risk of falling when using PIM }\end{array}$ & $\begin{array}{l}\text { Albert } 2010 \text { [73], } \\
\text { Ruggiero } 2010 \text { [74], } \\
\text { Passarelli } 2005[75], \\
\text { Dedhiya } 2010[76], \\
\text { Gallagher } 2008 \text { [42] }\end{array}$ \\
\hline Kaiser Permanente Model & $\begin{array}{l}\text { - lower likelihood of hospitalisation in } \\
\text { high-risk patients when using the Kaiser } \\
\text { Permanent Model of consultation }\end{array}$ & McCombs 1998 [77] \\
\hline Lipton Criteria & $\begin{array}{l}\text {-association between the prescribing } \\
\text { scores and the number of reported } \\
\text { adverse effects }\end{array}$ & Lipton 1993 [78] \\
\hline STOPP Criteria & $\begin{array}{l}\text { - increased risk for ADEs and hospital admission } \\
\text { in patients with PIM } \\
\text { according to STOPP }\end{array}$ & $\begin{array}{l}\text { Hamilton } 2011[79] \\
\quad \text { Gallagher } 2008 \text { [42] }\end{array}$ \\
\hline NCQA Criteria & $\begin{array}{l}\text { - Increased risk of hospitalisation with } \\
\text { medication on the NCQA list }\end{array}$ & Albert 2010 [73] \\
\hline
\end{tabular}


of a study or classification of the tool were discussed by at least three authors.

\section{Conclusion}

Through a systematic literature search we identified 46 different tools to assess inappropriate prescribing showing a large variety in methodological aspects and in clinical validation. Not surprisingly with such a variety of tools in such a complex field, this overview could not identify a single ideal tool but may help readers to choose one, either for research purposes or for daily practice use, according to the situation in which it is intended to be applied. By outlining the characteristics in a highly structured manner, this overview may reveal strengths and weaknesses, and thus, may stimulate further research in this area.

Conflicts of interest The authors declare that they have no conflicts of interest.

Contributions of authors statement (with relevance to the ICMJE Guidelines) C. P. Kaufmann: Contribution to the study design and the analysis and interpretation of data, involvement in the literature search, manuscript writing, final approval of the version to be published.

R. Tremp: Contribution to the study design and the analysis and interpretation of data, conducted the literature search and the mapping of the different tools.

K.E. Hersberger: Manuscript review and final approval of the version to be published.

M.L. Lampert: Contribution to the study design and the analysis and interpretation of data, manuscript review and final approval of the version to be published

\section{References}

1. Barber N (1995) What constitutes good prescribing? BMJ 310(6984):923-925

2. Shelton PS, Fritsch MA, Scott MA (2000) Assessing medication appropriateness in the elderly: a review of available measures. Drugs Aging 16(6):437-450

3. Spinewine A, Schmader KE, Barber N, Hughes C, Lapane KL, Swine C, Hanlon JT (2007) Appropriate prescribing in elderly people: how well can it be measured and optimised? Lancet 370(9582):173-184

4. Donabedian A (1981) Advantages and limitations of explicit criteria for assessing the quality of health care. Milbank Mem Fund Q Health Soc 59(1):99-106

5. Campbell SM, Cantrill JA (2001) Consensus methods in prescribing research. J Clin Pharm Ther 26(1):5-14

6. Chang CB, Chan DC (2010) Comparison of published explicit criteria for potentially inappropriate medications in older adults. Drugs Aging 27(12):947-957

7. Kaur S, Mitchell G, Vitetta L, Roberts MS (2009) Interventions that can reduce inappropriate prescribing in the elderly: a systematic review. Drugs Aging 26(12):1013-1028

8. Levy HB, Marcus EL, Christen C (2010) Beyond the Beers criteria: A comparative overview of explicit criteria. Ann Pharmacother 44(12):1968-1975
9. Dimitrow MS, Airaksinen MS, Kivela SL, Lyles A, Leikola SN (2011) Comparison of prescribing criteria to evaluate the appropriateness of drug treatment in individuals aged 65 and older: a systematic review. J Am Geriatr Soc 59(8):1521-1530

10. Parsons C, Johnston S, Mathie E, Baron N, Machen I, Amador S, Goodman C (2012) Potentially inappropriate prescribing in older people with dementia in care homes: a retrospective analysis. Drugs Aging 29(2):143-155

11. Mimica Matanovic S, Vlahovic-Palcevski V (2012) Potentially inappropriate medications in the elderly: a comprehensive protocol. Eur J Clin Pharmacol 68(8):1123-1138

12. Hanlon JT, Schmader KE, Ruby CM, Weinberger M (2001) Suboptimal prescribing in older inpatients and outpatients. J Am Geriatr Soc 49(2):200-209

13. Simonson W, Feinberg JL (2005) Medication-related problems in the elderly : defining the issues and identifying solutions. Drugs Aging 22(7):559-569

14. Robertson KE (1996) Process for preventing or identifying and resolving problems in drug therapy. Am J Health Syst Pharm 53(6):639-650

15. Wehling M (2009) Multimorbidity and polypharmacy: how to reduce the harmful drug load and yet add needed drugs in the elderly? Proposal of a new drug classification: fit for the aged. J Am Geriatr Soc 57(3):560-561

16. Haque R (2009) ARMOR: A Tool to Evaluate Polypharmacy in Elderly Persons. Annals of Long-Term Care 17(6):26-30

17. Sloane PD, Gruber-Baldini AL, Zimmerman S, Roth M, Watson L, Boustani M, Magaziner J, Hebel JR (2004) Medication undertreatment in assisted living settings. Arch Intern Med 164(18):2031-2037

18. Aronson JK (2004) Rational prescribing, appropriate prescribing. $\mathrm{Br}$ J Clin Pharmacol 57(3):229-230

19. Beers MH, Ouslander JG, Rollingher I, Reuben DB, Brooks J, Beck JC (1991) Explicit criteria for determining inappropriate medication use in nursing home residents. Arch Intern Med 151(9):1825-1832

20. Beers MH (1997) Explicit criteria for determining potentially inappropriate medication use by the elderly. An update Arch Intern Med 157(14):1531-1536

21. Fick DM, Cooper JW, Wade WE, Waller JL, Maclean JR, Beers MH (2003) Updating the Beers criteria for potentially inappropriate medication use in older adults: results of a US consensus panel of experts. Arch Intern Med 163(22):2716-2724

22. McLeod PJ, Huang AR, Tamblyn RM, Gayton DC (1997) Defining inappropriate practices in prescribing for elderly people: a national consensus panel. CMAJ 156(3):385-391

23. Hanlon JT, Schmader KE, Samsa GP, Weinberger M, Uttech KM, Lewis IK, Cohen HJ, Feussner JR (1992) A method for assessing drug therapy appropriateness. J Clin Epidemiol 45(10): 1045-1051

24. Malone DC, Abarca J, Hansten PD, Grizzle AJ, Armstrong EP, Van Bergen RC, Duncan-Edgar BS, Solomon SL (2003) Lipton RB (2004) Identification of serious drug-drug interactions: results of the partnership to prevent drug-drug interactions. J Am Pharm Assoc 44(2): $142-151$

25. Taylor LK, Kawasumi Y, Bartlett G, Tamblyn R (2005) Inappropriate prescribing practices: the challenge and opportunity for patient safety. Healthc Q 8:81-85

26. Terrell KM, Perkins AJ, Dexter PR, Hui SL, Callahan CM, Miller DK (2009) Computerized decision support to reduce potentially inappropriate prescribing to older emergency department patients: a randomized, controlled trial. J Am Geriatr Soc 57(8):1388-1394

27. Matsumura Y, Yamaguchi T, Hasegawa H, Yoshihara K, Zhang Q, Mineno T, Takeda H (2009) Alert system for inappropriate prescriptions relating to patients' clinical condition. Methods Inf Med 48(6):566-573 
28. Barenholtz Levy H (2003) Self-administered medication-risk questionnaire in an elderly population. Ann Pharmacother 37(7-8):982987

29. American Geriatrics Society Updated Beers Criteria for Potentially Inappropriate Medication Use in Older Adults (2012) J Am Geriatr Soc 60(4):616-631

30. Wenger NS, Shekelle PG (2001) Assessing care of vulnerable elders: ACOVE project overview. Ann Intern Med 135(8 Pt 2):642-646

31. Shekelle PG, MacLean CH, Morton SC, Wenger NS (2001) Acove quality indicators. Ann Intern Med 135(8 Pt 2):653-667

32. Wenger NS, Roth CP, Shekelle P (2007) Introduction to the assessing care of vulnerable elders-3 quality indicator measurement set. J Am Geriatr Soc 55(Suppl 2):S247-252

33. Mann E, Bohmdorfer B, Fruhwald T, Roller-Wirnsberger RE, Dovjak P, Duckelmann-Hofer C, Fischer P, Rabady S, Iglseder B (2012) Potentially inappropriate medication in geriatric patients: the Austrian consensus panel list. Wien Klin Wochenschr 124(5-6):160169

34. Schwalbe O, Freiberg I, Kloft C (2007) The beers criteria-an instrument to optimise the pharmacotherapy of geriatric patients. Med Monatsschr Pharm 30(7):244-248

35. Laroche ML, Charmes JP, Merle L (2007) Potentially inappropriate medications in the elderly: a French consensus panel list. Eur J Clin Pharmacol 63(8):725-731

36. Lindblad CI, Hanlon JT, Gross CR, Sloane RJ, Pieper CF, Hajjar ER, Ruby CM, Schmader KE (2006) Clinically important drug-disease interactions and their prevalence in older adults. Clin Ther 28(8):1133-1143

37. National Committee for Quality Assurance (NCQA) (2008) HEDIS High Risk Medications (DAE-A) and potentially harmful DrugDisease Interactions (DDE) in the Elderly. www.ncqa.org/tabid/598/ Default.aspx. assessed 10.02.2011

38. Rognstad S, Brekke M, Fetveit A, Spigset O, Wyller TB, Straand J (2009) The Norwegian General Practice (NORGEP) criteria for assessing potentially inappropriate prescriptions to elderly patients. A modified Delphi study. Scand J Prim Health Care 27(3):153-159

39. Rancourt C, Moisan J, Baillargeon L, Verreault R, Laurin D, Gregoire JP (2004) Potentially inappropriate prescriptions for older patients in long-term care. BMC Geriatr 4:9

40. Barry PJ, Gallagher P, Ryan C, O'Mahony D (2007) START (screening tool to alert doctors to the right treatment)-an evidence-based screening tool to detect prescribing omissions in elderly patients. Age Ageing 36(6):632-638

41. Gallagher P, Ryan C, Byrne S, Kennedy J, O'Mahony D (2008) STOPP (Screening Tool of Older Person's Prescriptions) and START (Screening Tool to Alert doctors to Right Treatment). Consensus validation. Int J Clin Pharmacol Ther 46(2):72-83

42. Gallagher P, O'Mahony D (2008) STOPP (Screening Tool of Older Persons' potentially inappropriate Prescriptions): application to acutely ill elderly patients and comparison with Beers' criteria. Age Ageing 37(6):673-679

43. Holt S, Schmiedl S, Thurmann PA (2010) Potentially inappropriate medications in the elderly: the PRISCUS list. Dtsch Arztebl Int 107(31-32):543-551

44. Holt S, Schmiedl S, Thürmann PA (2011) PRISCUS-Liste potenziell inadäquater Medikation für ältere Menschen. http://priscus.net/ download/PRISCUS-Liste PRISCUS-TP3 2011.pdf. Accessed 01. 02.2011

45. Winit-Watjana W, Sakulrat P, Kespichayawattana J (2008) Criteria for high-risk medication use in Thai older patients. Arch Gerontol Geriatr 47(1):35-51

46. Zhan C, Sangl J, Bierman AS, Miller MR, Friedman B, Wickizer SW, Meyer GS (2001) Potentially inappropriate medication use in the community-dwelling elderly: findings from the 1996 Medical Expenditure Panel Survey. JAMA 286(22):2823-2829
47. Maio V, Del Canale S, Abouzaid S (2010) Using explicit criteria to evaluate the quality of prescribing in elderly Italian outpatients: a cohort study. J Clin Pharm Ther 35(2):219-229

48. American Medical Directors Association (AMDA) Top 10 Particularly Dangerous Drug Interactions in Long Term Care. AMDA. http://www.amda.com/tools/clinical/m3/topten.cfm. Accessed 07. 04. 2011

49. Raebel MA, Charles J, Dugan J, Carroll NM, Korner EJ, Brand DW, Magid DJ (2007) Randomized trial to improve prescribing safety in ambulatory elderly patients. J Am Geriatr Soc 55(7):977-985

50. Lechevallier-Michel N, Gautier-Bertrand M, Alperovitch A, Berr C, Belmin J, Legrain S, Saint-Jean O, Tavernier B, Dartigues JF, FourrierReglat A (2005) Frequency and risk factors of potentially inappropriate medication use in a community-dwelling elderly population: results from the 3C Study. Eur J Clin Pharmacol 60(11):813-819

51. Bachyrycz A, Dodd MA, Priloutskaya G (2012) Development and dissemination of a statewide system to minimize use of Potentially Inappropriate Medications (PIMs). Med Care 50(11):993-996

52. Centre of Medicare and Medicaid Services (CMS) (2006) List of unnecessary Medications Used in Residents of Long-Term Care Facilities http://www.cms.gov/Regulations-and-Guidance/Guidance/ Transmittals/downloads/R22SOMA.pdf. Accessed 22.03. 2011

53. Naugler CT, Brymer C, Stolee P, Arcese ZA (2000) Development and validation of an improving prescribing in the elderly tool. Can $\mathrm{J}$ Clin Pharmacol 7(2):103-107

54. Sloane PD, Zimmerman S, Brown LC, Ives TJ, Walsh JF (2002) Inappropriate medication prescribing in residential care/assisted living facilities. J Am Geriatr Soc 50(6):1001-1011

55. Kolzsch M, Bolbrinker J, Huber M, Kreutz R (2010) Potentially inappropriate medication for the elderly: adaptation and evaluation of a French consensus list. Med Monatsschr Pharm 33(8):295-302

56. Frohnhofen H, Michalek C, Wehling M (2011) Assessment of drug treatment in geriatrics with the new FORTA criteria. Dtsch Med Wochenschr 136(27):1417-1421

57. Cantrill JA, Sibbald B, Buetow S (1998) Indicators of the appropriateness of long-term prescribing in general practice in the United Kingdom: consensus development, face and content validity, feasibility, and reliability. Qual Health Care 7(3):130-135

58. Lipton HL, Bero LA, Bird JA, McPhee SJ (1992) The impact of clinical pharmacists' consultations on physicians' geriatric drug prescribing. A randomized controlled trial. Med Care 30(7):646-658

59. Winslade NE, Bajcar JM, Bombassaro AM, Caravaggio CD, Strong DK, Yamashita SK (1997) Pharmacist's management of drug-related problems: a tool for teaching and providing pharmaceutical care. Pharmacotherapy 17(4):801-809

60. Hamdy RC, Moore SW, Whalen K, Donnelly JP, Compton R, Testerman F, Haulsee P, Hughes J (1995) Reducing polypharmacy in extended care. South Med J 88(5):534-538

61. Owens NJ, Fretwell MD, Willey C, Murphy SS (1994) Distinguishing between the fit and frail elderly, and optimising pharmacotherapy. Drugs Aging 4(1):47-55

62. Basger BJ, Chen TF, Moles RJ (2008) Inappropriate medication use and prescribing indicators in elderly Australians: development of a prescribing indicators tool. Drugs Aging 25(9):777-793

63. Basger BJ, Chen TF, Moles RJ (2012) Validation of prescribing appropriateness criteria for older Australians using the RAND/ UCLA appropriateness method. BMJ Open 2(5)

64. Brown NJ, Griffin MR, Ray WA, Meredith S, Beers MH, Marren J, Robles M, Stergachis A, Wood AJ, Avorn J (1998) A model for improving medication use in home health care patients. J Am Pharm Assoc (Wash) 38(6):696-702

65. New South Wales Therapeutic Advisory Group (2007) Indicators for Quality Use of Medicines in Australian Hospitals. http://www.ciap. health.nsw.gov.au/nswtag/documents/publications/indicators/ manual.pdf. Accessed 01.05. 2011 
66. Oborne CA, Batty GM, Maskrey V, Swift CG, Jackson SH (1997) Development of prescribing indicators for elderly medical inpatients. Br J Clin Pharmacol 43(1):91-97

67. Oborne CA, Hooper R, Swift CG, Jackson SH (2003) Explicit, evidence-based criteria to assess the quality of prescribing to elderly nursing home residents. Age Ageing 32(1):102-108

68. Lee SS, Schwemm AK, Reist J, Cantrell M, Andreski M, Doucette WR, Chrischilles EA, Farris KB (2009) Pharmacists' and pharmacy students' ability to identify drug-related problems using TIMER (Tool to Improve Medications in the Elderly via Review). Am J Pharm Educ 73(3):52

69. Newton PF, Levinson W, Maslen D (1994) The geriatric medication algorithm: a pilot study. J Gen Intern Med 9(3):164-167

70. Johnson KA, Nye M, Hill-Besinque K, Cody M (1995) Measuring of impact of patient counseling in the outpatient pharmacy setting: development and implementation of the counseling models for the Kaiser Permanente/USC Patient Consultation Study. Clin Ther 17(5):988-1002

71. Bergman-Evans B (2006) Evidence-based guideline. Improving medication management for older adult clients. J Gerontol Nurs 32(7):6-14

72. Drenth-van Maanen AC, van Marum RJ, Knol W, van der Linden CM, Jansen PA (2009) Prescribing optimization method for improving prescribing in elderly patients receiving polypharmacy: results of application to case histories by general practitioners. Drugs Aging 26(8):687-701
73. Albert SM, Colombi A, Hanlon J (2010) Potentially inappropriate medications and risk of hospitalization in retirees: analysis of a US retiree health claims database. Drugs Aging 27(5):407-415

74. Ruggiero C, Dell'Aquila G, Gasperini B, Onder G, Lattanzio F, Volpato S, Corsonello A, Maraldi C, Bernabei R, Cherubini A (2010) Potentially inappropriate drug prescriptions and risk of hospitalization among older, Italian, nursing home residents: the ULISSE project. Drugs Aging 27(9):747-758

75. Passarelli MC, Jacob-Filho W, Figueras A (2005) Adverse drug reactions in an elderly hospitalised population: inappropriate prescription is a leading cause. Drugs Aging 22(9):767-777

76. Dedhiya SD, Hancock E, Craig BA, Doebbeling CC, Thomas J 3rd (2010) Incident use and outcomes associated with potentially inappropriate medication use in older adults. Am J Geriatr Pharmacother 8(6):562-570

77. McCombs JS, Liu G, Shi J, Feng W, Cody M, Parker JP, Nichol MB, Hay JW, Johnson KA, Groshen SL, Nye MT (1998) The Kaiser Permanente/USC Patient Consultation Study: change in use and cost of health care services. Am J Health Syst Pharm 55(23):2485-2499

78. Lipton HL, Bird JA, Bero LA, McPhee SJ (1993) Assessing the appropriateness of physician prescribing for geriatric outpatients. Development and testing of an instrument. J Pharm Technol 9(3):107-113

79. Hamilton H, Gallagher P, Ryan C, Byrne S, O'Mahony D (2011) Potentially inappropriate medications defined by STOPP criteria and the risk of adverse drug events in older hospitalized patients. Arch Intern Med 171(11):1013-1019 